\title{
Resilience, Shyness and Loneliness as Predictors of Internet Addiction among University Undergraduate Students in Benue State
}

\author{
Joyce M. Terwase, Ph.D ${ }^{1,}$ Reuben Lubem Ibaishwa ${ }^{2}$ \\ Department of Psychology, Benue State University, Makurdi, Nigeria
}

\begin{abstract}
The paper examined the resilience, shyness and loneliness as predictors of internet addiction among university undergraduate students in Benue State. An ex post facto design was adopted. A total of 473 undergraduate students were purposively selected from two universities within Makurdi Benue State, Nigeria, to participate in the study. Simple regression analysis revealed that resilience negatively predicted internet addiction while shyness and loneliness positively predicted internet addiction. However, emotional aspect of loneliness was found to negatively predict internet addiction while social aspect of loneliness positively predicts internet addiction. It was concluded based on the results of the study that resilience, shyness and loneliness significantly predict internet addiction. Based on the findings, it was recommended that psychological counselling services can be provided for undergraduate students who have higher levels of internet addiction. Further, more comprehensive studies can be carried out to examine the relation between internet addiction and such variables like resilience, shyness and loneliness.
\end{abstract}

Keywords: Internet Addiction, Loneliness, Resilience, Shyness, University Undergraduate Students

\section{Introduction}

The internet has revolutionized the flow of information and communication between people, changing the way we interact with others, gather and disseminate information, do business, carry out academic activities, express and entertain ourselves. Just like the rest of the world, Nigeria has embraced the internet and a remarkable ongoing progress has been achieved in various domains (education, information, professional engagement, entertainment etc.). The internet has become an integral part of undergraduates' lives. The increased time undergraduates are spending online is prompting questions about whether they are in control of their internet usage. Concerns have been expressed that too much time on the internet can negatively influence several aspects of young people's lives, perhaps leading to: declining school results or even dropping out of school; increased family tension; abandoned hobbies; psychological problems such as depression, anxiety, low self-esteem; and physical health problems due to sleep deprivation and lack of physical activity [1].

With the availability and mobility of new media, Internet addiction has emerged as a potential problem in young people. Based on a growing research base [2], the American Psychiatric Association include Internet Use Disorder in the appendix of the fifth edition of the Diagnostic and Statistical Manual for Mental Disorders (2012) for the first time, acknowledging the problems arising from this type of addictive disorder.

The advancement in information technology and the existence of interactive social media have occasioned research interest in the area of problematic use of the new forms of communication and media. Internet addiction was a coinage of Goldberg [3] to describe the undesirable consequences emanating from excessive internet usage on individual lives. Internet addiction shares certain degree of similarity with substance addiction where addicts suffer mentally and physically. As observed by Griffiths [4]; Kandell [5], this nonsubstance addiction is however viewed as severe psychological dependency and behavioural addiction to the internet.

The concept of addiction follows the medical model. Addiction, in the medical model relates with bodily and psychological dependence on a physical substance and not on behavioural pattern. It has been argued that addiction should be widened to cover a broader range of behaviour $[6,7,8]$. These researchers proposed a subset of behavioural addiction- the concept of technological addiction. Young [9] presented a definition of internet-related disorder called 'Problematic Internet Use (PIU) and noted that internet use interfered with addicts' academic work, social lives and professional performance. Probing further the researcher identified skipping sleep, ignoring family responsibilities, and showing up late for work or academic as some attendant outcomes. These are evidences of psychological disorder which meet up with the criteria for impulse control disorder, mental illness characterized by an uncontrollable desire to perform behaviour [10]

With regards to prevalence of internet addiction in young people, estimates vary widely across countries. Using Young's Internet Addiction Test [11], 1.5\% of Greek [12] and 1.6\% of Finnish adolescents 
[13] were found to be addicted to using the internet. Using a modified version of the Minnesota Impulsive Disorders Inventory, 4\% of U.S high schools were identified as addicted to using the internet [14]. Higher prevalence rates have been reported in South East Asian countries (e.g., Taiwan, Singapore, South Korea and China). For example, using Young's Internet Addiction Test [15] 8\% of adolescents in China [16] and 10.7\% of adolescents in South Korea [17] were found to be addicted to using the internet. In comparison and unsurprisingly, prevalence estimates in youth psychiatric settings are reported to be considerably higher. For instance, the prevalence of internet addiction among minors using the Assessment of Internet and Computer Game Addiction Scale [18] was found to be $11.3 \%$ in Germany [19] and accessed via the Internet Addiction Test [20], 11.6\% of adolescent outpatients in Latin America were classed as being internet addicts [21].

In Nigeria, Alabi [22] found low level addiction (1.6\%) particularly among university undergraduates in private universities. Although he observed low level of addiction, this result may be due to the low level of internet access generally in Nigeria and expensiveness of internet. Also, Alabi's study focused on undergraduates in private universities neglecting those in public universities where majority of Nigerians afford the payment for university education. Internet addiction research is a rather new research area in Nigeria, which has less than 10 years of history. Research efforts have been largely focused on the examination of the concept of internet use and its effect on academic performance with little spared for studies on problematic use of the internet in high-risk groups and how this addictive behaviour is linked to certain psychological variables. The current study attempted to address this research need, identifying predictors of internet addiction with a focus on resilience, shyness and loneliness. In brief, it assessed whether resilience shyness and loneliness predict internet addiction.

The term resilience is derived from the verb 'resile', which refers to when an object is stretched or bent; it tends to spring back, to recoil, and to resume its former shape and size. Resilience has become an important factor in research and mental health theory over the past decades [23,24]. Another scholar [25] sees resilience as the ability to maintain a state of normal equilibrium in the face of extremely unfavourable circumstance. Resilience has also been defined as the capability to flourish despite normative fluctuations that take place throughout the life span [26]. Furthermore, [27] stated that resilience is a psychological process developed in response to intense life stressor that facilitates healthy functioning. To be resilient includes constructive and growth-enhancing consequences of adversity or challenges [28]. While some people are naturally resilient, as their personality may contribute to the prediction of resilience, others may have to work at it [29,30]. It is, co-determined by environmental and personal characteristics [31]. With this review, we have hypothesized that:

H1 Resilience will positively predict internet addiction among undergraduate students in Benue State.

Shyness is another psychological variable in which the present research examined its predictive power on internet addiction among undergraduate students in Nigeria. Shyness is the fear to meet people and the discomfort in others' presence [32]. At its core is anxiety about being evaluated by others and consequently rejected [32]. It is associated with excessive monitoring of behaviour and takes the form of hesitation in making spontaneous utterances, reluctance to express opinions, and making responses to the overtures of others that reduce the likelihood of further interaction [33]. Shy people suffer numerous disadvantages. Compared with others, they more likely regard their networks (i.e., offline networks) as less supportive and less satisfying and are happy to be by themselves or to participate minimally in social encounters [34]. Jones and Carpenter [35] found that shy people had less social support, smaller friendship networks, and fewer, more passive interactions in their offline lives than the non-shy people.

The internet offers an alternative for people to gratify their social and emotional needs, which might be unmet in their traditional offline networks [36]. In the faceless cyberspace, people can create online personas where they alter their identities and pretend to be someone other than themselves [33]. They can enjoy aspects of the internet that allow them to meet, socialize, and exchange ideas through the use of e-mail, chat rooms and newsgroups, which in turn allow the person to fulfil unmet emotional and psychological needs that are more intimate and less threatening than real life relationships [33]. Shyness or anxiety does not pose an obstacle to the use of e-mail and chat rooms [37]. Research has proposed that the computer-mediated medium is the perfect environment for shy people because of their greater perceived control over the communication process, such as the absence of time constraints in preparing messages and the absence of direct observation by others. According to Liebert [33] anonymity in virtual environments provides shy individuals with a safe and secure environment for social interaction. In fact, as it has been said, "in the Internet, no one knows you are an introvert".

Past research has investigated the relationship between shyness and internet disorder and found that increased shyness significantly correlate to internet addiction [38, 39, 40]. Other anecdotal accounts also suggested that reduced shyness in social synchronous virtual environments, such as Internet Relay Chat and Multi-User Dimensions, might also influence the level of internet use. Based on this brief review of the literature, we hypothesized that 
H2. Shyness will positively predict internet addiction among undergraduate students in Benue State.

Apart from resilience and shyness, another variable that we examined its predictive power on internet addiction was loneliness. Loneliness has been described as negative feelings that exist when there is a discrepancy between what one wants in terms of interpersonal affection and intimacy and what one, in fact, has [41]. Blazer [42] reported that the discrepancy can be long standing or can result from changes in the individual's social relations or changes in the person's social needs or desires. Moreover, Peplua and Perlman [43] described loneliness as a subjectively experienced aversive emotional state that is related to the perception of unfulfilled intimate and social needs. Furthermore, loneliness involves the cognitive awareness of a deficiency in one's social and personal relationships, and leads to affective reactions of sadness, emptiness, or longing [44]. This can occur not only when people lack ongoing relationships with others, but even when they have meaningful relationships that take negative turns. For example, loneliness can be a response to separations, such as when a friend is unavailable to play with or moves away leaving behind affectionately stranded friends [44]. Rokach [45] proposed three distinguishing characteristics of all loneliness experiences: Loneliness is a universal phenomenon, a subjective experience, and a multifaceted experience. It is always very painful, severely distressing, and individualistic.

Psychosocial disorders such as loneliness and depression are indirect results of internet addiction [46]. Lonely people often show symptoms of depression and anger while also demonstrating a tendency to misunderstand people [47]. Students who are addicted to the internet are students who are lonely and lack interaction with other people. This implies that students who are lonely need companions to chat with. As a result, they crave for internet for social interaction. In regard to the review, the study hypothesized that:

H3 Loneliness will positively predict internet addiction among undergraduate students in Benue State.

\section{Method}

\subsection{Research Design}

The design is an ex post facto. The predictor variables are resilience, shyness and loneliness. The criterion variable is internet addiction which was measured as a single or composite construct.

\subsection{Research Setting}

The study was conducted at Benue State University and University of Agriculture, both in Makurdi, Benue State, Nigeria. Makurdi is the state capital of Benue State with high number of undergraduate students.

\subsection{Participants}

The target population was undergraduate university students studying to acquire a university degree. Their ages ranged from 18 years and above, with 306 (64.7\%) males and 167 (35.3\%) females. Respondents varied on their level of study, course of study, religion, ethnicity and marital status.

\subsection{Instruments}

A questionnaire was used, comprising four sections. The first section measured the demographic characteristics like age, sex, level of study, course of study religion, ethnicity and marital status. The second section contained items from the new resilience scale developed by Ryan and Caltabiano [48]. 21 items were extracted from the new resilience scale which consists of 25 items. These items were extracted through itemtotal correlation. Item-total correlation analysis yielded 21 items, using . 30 as the criterion selection. The scale is self-rated on a 5-point scale (0-4), with higher scores reflecting greater resilience. The coefficient alpha value of the scale is. 72 .

The third section measured shyness. This section contained 9 items extracted from the 13 items revised Cheek and Buss Shyness Scale. Item-total correlation analysis yielded 9 items, using .30 as the criterion selection. The coefficient alpha value of the shyness scale is .77. Items were scored using a 5-point Likert scale, namely, " $1 "=$ "strongly disagree" and " $5 "=$ "strongly agree."

The fourth section of the questionnaire contained 10 items extracted from the 11 items De Jong Gierveld Loneliness Scale [49,50]. Item-total correlation analysis yielded 10 items using .30 criterion selection. The loneliness scale scores ranges from 0 (not lonely) to 11 (extremely lonely) $(\alpha=.84$ ). The scale has proved to be a reliable and valid instrument [51]. The scale has two subscales (emotional loneliness and social loneliness, with $\alpha=.88$ and $\alpha=.88$, respectively). The scale was used both as a univariate construct by using the composite score to assess the overall level of undergraduate's loneliness, as well as a multidimensional construct because of its subscales i.e. emotional loneliness and social loneliness. The respective coefficient alpha value of overall loneliness, emotional loneliness and social loneliness obtained for this study are $.67, .72$ and .69 respectively.

The fifth section of the scale measured internet addiction. Internet Addiction Test (IAT) [9], a 20-item scale which evaluates the degree of preoccupation, compulsive use, behavioural problems, emotional changes, 
and impact upon functionality consequent to internet utilization. The Internet Addiction test was adopted from the work of Tsitsika, Janikian, Tzavela, Schoenmakers, Ólafsson, Halapi, Tzavara, Wójcik, Makaruk, Critselis, Müller, Dreier, Holtz, Wölfling, Iordache, Oliaga, Chele, Macarie and Richardson [52]. Tsitsika, et al. [52] modified the phrasing of Young's Internet Addiction Test. The questionnaire has a high reliability (Cronbach's alpha $=.92$ ). Item-total correlation analysis yielded 17 items using .30 as criterion for selection. A reliability cronbach alpha of .86 was obtained.

\subsection{Procedure}

In a pilot study designed to standardize the instrument for use among Nigerian undergraduate students, 50 undergraduate students participated. Items were retained only if their corrected item-total correlation is at least .30 and above for all the scales. For the main study, 500 questionnaires were distributed but 485 were returned; 3 were not filled, and 9 others eliminated because they were incompletely filled. Consequently, 473 questionnaires were used for the final analysis.

Participants were purposively selected for the study. The selected participants were informed of the objective of the study, and confidentiality assured, after their individual consent had been sought. The researchers did the administration of the questionnaires with the help of students who were trained on questionnaire administration.

\section{Results}

In answering the research hypotheses raised in the present study, simple regression analysis was used. Resilience, shyness and loneliness and its two facets; emotional loneliness and social loneliness, were regressed on dependent variable (internet addiction). The results are presented on Table 1, 2 and 3.

\section{Table 1: Summary of multiple regression analysis showing resilience, shyness and loneliness as predictors} of internet addiction

\begin{tabular}{|l|r|r|r|r|}
\hline Model & \multicolumn{1}{|c|}{ R } & R Square & Adjusted R Square & \multicolumn{2}{|c|}{ Std. Error of the Estimate } \\
\hline 1 & $.995^{\mathrm{a}}$ & .990 & .990 & .66911 \\
\hline
\end{tabular}

Table 2: Analysis of variance showing the resilience, shyness and loneliness on internet addiction

\begin{tabular}{|ll|r|r|r|r|r|}
\hline Model & & Sum of Squares & df & Mean Square & \multicolumn{1}{c|}{ F } & \multicolumn{1}{c|}{ Sig. } \\
\hline 1 & Regression & 7151.451 & 14 & 510.818 & 1140.947 & $.000^{\mathrm{a}}$ \\
& Residual & 69.396 & 155 & .448 & & \\
& Total & 7220.847 & 169 & & & \\
\hline
\end{tabular}

Table 3 Regression of Resilience, Shyness, Loneliness, Emotional Loneliness and Social Loneliness on

\begin{tabular}{|c|c|c|c|c|}
\hline \multicolumn{5}{|c|}{ Internet Addiction } \\
\hline Variables & Std. Error & Beta & $\mathrm{t}$ & $\mathrm{P}$ \\
\hline Resilience & .015 & -.683 & $64.48 * *$ & .000 \\
\hline Shyness & .015 & .238 & $56.89 * *$ & .000 \\
\hline Loneliness & .016 & .328 & $3.09 * *$ & .002 \\
\hline Emotional Loneliness & .013 & -.035 & $3.64 * *$ & .000 \\
\hline Social Loneliness & .017 & .016 & $.496 *$ & .03 \\
\hline
\end{tabular}

Note: $*=\mathbf{P}<.05$;

$$
* *=\mathbf{P}<.01
$$

The results of regression analyses revealed that among the variables tested to examined their predictive power on internet addiction, tested in the study, resilience $(\beta=-.683 ; \mathrm{p}<.01)$ negatively predicted internet addiction while shyness $(\beta=.238 ; p<.01)$; loneliness $(\beta=.328 ; p<.01)$, emotional loneliness $(\beta=-.035 ; p<$ $.01)$ negatively predicted internet addiction while social loneliness $(\beta=.016 ; \mathrm{p}<.05)$ positively predicted internet addiction. This result indicated that resilience which is the ability to maintain or regain positive levels of functioning despite adversity, is one of several factors that negatively influence undergraduates to become addictive to internet.

Finding from Table 3 also indicate that shyness which is the fear of an individual to meet people and the discomfort in others' presence positively predict internet addiction. This implies that an undergraduate student who has fear of people and feel discomfort in the presence of other individuals will become addictive to the internet. In a related development, loneliness was found to predict internet addiction. This means that an 
individual who is having way too insufficient social relations in terms of quality and quantity will be addicted to the internet. In other words, internet addiction may come as a result of an individual's reaction to the lack of emotional and social relations he needs or even though, he has the relations, the lack of intimacy, sincerity and emotion in those relations is what he needs.

The data in table 1 showed that the three independent variables, when taken together yielded a multiple regression coefficient (R) of .995 , a multiple $R$ square $\left(\mathrm{R}^{2}\right)$ of .990 . This means that .990 or 99.0 percent of the total variance in the internet addiction of undergraduate students can be explained by the combined influence of the three predictor variables (resilience, shyness, loneliness (emotional loneliness and social loneliness)).

In addition, the data in Table 2 shows that the analysis of variance of simple regression analysis yielded an $\mathrm{F}$ value of 1140.947 which is significant at 0.01 alpha level. This implies that resilience, shyness, loneliness, emotional loneliness and social loneliness jointly have a significant influence on internet addiction among undergraduate students.

\section{Discussion}

Internet addiction was first described by Kimberly Young in 1996 [53]. Since then, there have been many studies examining internet addiction in different parts of the world. The present study examined internet addiction among undergraduate students in Benue State, Nigeria. The simple regression analysis conducted revealed that all the predictor variables jointly predict internet addiction.

Contrary to the literature, resilience negatively predicted internet addiction. The results partially supported the findings of Akst [54] that resilience was a positive predictor of internet addiction. The result of the simple regression showed that shyness predicts internet addiction positively. This finding support those of Liebert [33]; Caplan [38]; Ofosu [39]; Goulet [40] who found that increased shyness significantly correlate to internet addiction. In related development, Chak [55] also found shyness to predict internet addiction. This finding implies that the shier an individual, higher the tendency of one being addicted to the internet, the shier the person is, the less faith the person has, the firmer belief the person holds in the irresistible power of others, and the higher trust the person places on chances in determining his or her own course of life there by becoming addicted to the internet. Shy people who are addicted to the internet make intense and frequent use of the internet both in terms of days per week and in length of each session, especially for online communication via email, ICQ, chat room, newsgroup and online games.

The third predictor variable in this study, loneliness, predicted internet addiction positively. However, emotional aspect of loneliness was found to negatively predict internet addiction while social aspect of loneliness positively predicts internet addiction. This finding implies that undergraduates who are lonely would be addictive to internet and would also feel more lively, valued and important while on internet. Further, undergraduates who are socially lonely will be more addictive to internet. This finding supports those of Ayaroglu [56]; Ceyhan [57]; Eldelekloglu [58]; Kim, LaRose and Peng [59]; Kurtaran [60]; Morahan-Martin and Schumacher [61]. This finding also supports those of Koc [62] who in his study on university students found that loneliness leads to internet addiction.

\section{Conclusion And Suggestions}

In this study, the internet addiction of university undergraduate students is examined in terms of resilience, shyness and loneliness (emotional loneliness and social loneliness). The results of the study indicated that resilience, shyness and loneliness significantly predict internet addiction. However, resilience and emotional loneliness were found to negatively predict internet addiction.

The advantage of the study is that it has highlighted the issue of internet addiction among university students in Benue state and Nigeria at large. The study showed that the predictor variables influence internet addiction.

\subsection{Limitations and Recommendations of the Study}

Overall, this study demonstrates increase understanding of resilience, shyness and loneliness on internet addiction among undergraduate students in Benue State. Although the results of the current study are interesting and have implications for interventions that could reduce internet addiction in undergraduate students, several limitations may have influenced the results. First, the sample did not represent all undergraduate students because of the purposive sampling. Therefore, caution need to be exercised in generalizing the findings of this study to undergraduate students. Second, the data in the current study were gathered at one point in time. Consequently, the respondents' perception may have been influenced by covariate factors. Thus, the interpretation of the results is constrained by the cross- sectional nature of the data. In addition, the current study was limited to self-report data, which may raises the potential problems with desirability bias and tiredness, thereby affecting the result of the study. 
Based on the limitations, the findings should be interpreted cautiously and the findings need to be replicated with more representative sample of undergraduate students. In general, there is an obvious need to carry out further research to investigate the variables explored herein with large samples spanning multiple cultures or different ages, and with other populations, such as children and younger adolescents, older adults. Future studies should continue to explore other factors that might contribute to internet addiction. In addition, there is a need for interventional studies aimed at helping undergraduate students who experience chronic internet addiction. More so, research replicating the present study could also be performed to either confirm or repudiate the findings of the study.

This study has several practical implications for university psychotherapist and parents. University undergraduate students who are addicted to the internet may lack social support, social skills and have interpersonal deficiency. The findings of the present study suggest that university psychotherapist and counselors can develop counseling and treatment interventions better tailored for internet addict students if resilience, shyness and loneliness are addressed. Programs can also be designed to better educate students, parents, and faculty members about contributing factors to internet addiction, how to identify them and how to properly approach these factors. Improving students' self worth, enhancing their self-efficacy and providing support may contribute to better psychotherapy, counseling and treatment programs for internet addicted undergraduate students.

References

[1]. K.S. Young, and C.N. de Abreu, (eds), Internet addiction: A handbook and guide to evaluation and treatment (Hoboken, NJ: John Wiley \& Sons, Inc., 2011).

[2]. K.S. Young, Internet addiction over the decade: A personal look back. World Psychiatry, 9(2), 2010, 91-91.

[3]. I. Goldberg, Internet addiction disorder, 1996. Retrieved June 3, 2014 from http://www.rider.edu/suler/psycyber/supportgp.html.

[4]. M. Griffiths, Does internet and computer 'addiction' exist? Some case study evidence'. Cyber Psychology and Behaviour, 3(2), $2000,211-18$.

[5]. J.J. Kandell, Internet addiction on campus: The vulnerability of college students. Cyber Psychology \& Behaviour. 1, 1998, 11-17.

[6]. S. Byun, C. Ruffini, J.E. Mills, A.C. Douglas, M. Niang, T. Stepehenkovia, S.K. Lee, J. Loutfi, J. Lee, M. Atallah, and M. Blanton, Internet addiction: Meta synthesis of 1996-2006 quantitative research. Cyber Psychology and Behaviour, 12(2), 2009, $202-207$.

[7]. M. Griffiths, Internet addiction: An issue for clinical psychology? Clinical Psychology, 97, 1996, 32-36.

[8]. J. Lemon, Can we call behaviour addiction? Clinical Psychologist, 6, 2002, 41-48.

[9]. K.S. Young, Internet addiction: The emergence of a new clinical disorder. Cyber Psychology and Behaviour, 1(3), 1998a, $237-244$.

[10]. L. Lous, and S.N. Paul, The influence of information literacy, internet addiction and parenting styles on internet risk. New Media and Society, 14 (1), 2012, 117-136.

[11]. K.S. Young, Internet addiction: Symptoms, evaluation and treatment in Vande Creek, L. , \& Jackson, T. Innovations in Clinic Practice: A source book. 17, 1999, 19-31.

[12]. G. Kormas, E., Critselis, M. Janikian, D. Kafetzis, and A. Tsitsika, Risk factors and psychosocial characteristics of potential problematic and problematic internet use among adolescents: A cross-sectional study. BMC Public Health, 11, $2011,45-57$.

[13]. R. Kaltiala-Heino, T. Lintonen, and A. Rimpela, Internet addiction: Potentially problematic use of the Internet in a population of 12-18 year-old adolescents. Addiction Research and Theory, 12 (1), 2004, 89-96.

[14]. T.C. Liu, R.A. Desai, S. Krishnan-Sarin, D.A. Cavallo, and M.N. Potenza, Problematic internet use and health in adolescents: Data from a high school survey in connecticut. Journal of Clinical Psychiatry, 72(6), 2011, 836-845.

[15]. K.S. Young, Caught in the net: How to recognize the signs of internet addiction - and a winning strategy for recovery. (New York, Wiley, 1998b).

[16]. H. Cao, Y. Sun, Y. Wan, J. Hao, and F. Tao, Problematic internet use in Chinese adolescents and its relation to psychosomatic symptoms and life satisfaction. BMC Public Health, 11, 2011, 14-25.

[17]. S. K. Park, J.Y. Kim, and C.B. Cho, Prevalence of internet addiction and correlates with family factors among South Korean adolescents. Adolescence, 43 (172), 2008, 895-909.

[18]. K. Wölfling, K. Müller, and M. Beutel, Diagnostic measures: Scale for the assessment of internet and computer game addiction (AICA-S). In D. Mücken, A. Teske, F. Rehbein \& B. te Wildt (Eds.), Prevention, diagnostics, and therapy of computer game addiction (Lengerich: Pabst Science, 2010) 212-215.

[19]. K. W. Müller, M. Ammerschläger, F.J. Freisleder, M.E. Beutel, and K. Wölfling, Addictive internet use as a comorbid disorder among clients of an adolescent psychiatry - Prevalence and psychopathological symptoms. [Suchtartige Internetnutzung als komorbide Störung im jugendpsychiatrischen Setting. Zeitschrift für Kinder- und Jugendpsychiatrie und Psychotherapie, 40(5), 2012, 331-339.

[20]. K.S. Young, Internet addiction: The emergence of a new clinical disorder. Cyber Psychology and Behaviour, 1(3), 1998a, $237-244$.

[21]. K.A. Liberatore, K. Rosario, L.N. Colon-De Marti, and K.G. Martinez, Prevalence of internet addiction in Latino adolescents with psychiatric diagnosis. Cyberpsychology, Behaviour and Social Networking, 14 (6), 2011, 399-402.

[22]. O.F. Alabi, A survey of face book addiction level among selected Nigerian university undergraduates. New Media and Mass Communication, 10, 2013, 70-81.

[23]. M. Achour, and M.R.M. Nor, The effects of social support and resilience on life satisfaction of secondary school students. Journal of Academic and Applied Studies (Special Issue on Applied Sciences), 4(1), 2014, 12-20.

[24]. F. Walsh, Family resilience: A framework for clinical practice. Family Process, 42(1), 2003, 1-18.

[25]. G. Bonanno, Loss, trauma and human resilience: Have we underestimated the human capacity to thrive after extremely aversive events? American Psychologist, 59 (1), 2004, 20-28.

[26]. M.E.P. Seligman, and M. Csikszentmihalyi, Positive psychology: An introduction. American Psychologist, 55, $2000,5-14$.

[27]. D.C. Johnson, M.A. Polusny, C.R. Erbes, D. King, L. King, B.T. Litz, P.P Schnurr, M. Friedman, R.H. Pietrzak, and S.M. Southwick, Resilience and response to stress: Development and initial validation of the response to stressful experiences scale (RSES). Naval Health Research Center, San Diego, CA. 2008.

[28]. D.J.W. Strumpfer, Resilience and burnout: A stitch that could save nine. South African Journal of Psychology, 33(2), 2003, 69-79. 
[29]. L. Campbell-Sills, L. Cohan, and M. Stein, Relationship of resilience to personality, coping, and psychiatric symptoms in young adults. Behaviour Research and Therapy, 44, 2006, 585-599.

[30]. D. Griffith, A New Year's Resolution for Your Emotional Health, (2007). Retrieved May 2, 2014, from www.healthatoz.com.

[31]. C.C. Lew, A Factor Analytical Study of Adult Career Concerns, Career Status and Career Resilience, doctorate dissertation, Rand Afrikaans University, South Africa, 2001.

[32]. P.A. Pilkonis,. Shyness, public and private, and its relationship to other measures of social behavior. Journal of Personality, 45, 1977, 585-595.

[33]. M.A. Liebert, The online disinhibition effect. Cyber Psychology and Behaviour, 7(3), 2004, $321-327$.

[34]. L. Parrott, Helping the struggling adolescent: A guide to thirty-six common problems for counselors, pastors, and youth workers (Grand Rapids, Mich: Zondervan Pub. House, 2000).

[35]. W.H. Jones, and B.N. Carpenter, Shyness, social behaviour, and relationships. In W. H. Jones, J. M. Cheek, \& S. R. Briggs (eds.). Shyness: Perspectives on Research and Treatment (New York: Plenum Press, 1986) 227-366.

[36]. L. Leung, Impacts of net-generation attributes, seductive properties of the internet, and gratifications-obtained on internet use. Telematics \& Informatics, 20 (2), 2003, 107-129.

[37]. M. Scealy, J.G. Phillips, and R. Stevenson, Shyness and anxiety as predictors of patterns of Internet usage. Cyber Psychology \& Behaviour, 5(6), 2002, 507-515.

[38]. S. E. Caplan, Problematic internet use and psychosocial well-being: Development of a theory-based cognitive-behavioural measurement instrument. Computers in Human Behaviour, 18, 2002, 553-575.

[39]. H. B. Ofosu, Heavy internet use: A proxy for social interaction. Dissertation Abstracts International: Section B: The Sciences and Engineering 61(9-B), 2001, 5058.

[40]. N. Goulet, The effect of internet use and internet dependency on shyness, loneliness, and self-consciousness in college students. Dissertation Abstracts International: Section B: The Sciences and Engineering, 63, 2002, 2650.

[41]. W. Lauder, S. Siobhan, and M. Kerry, Community survey of loneliness. Journal of Advanced Nursing, 46, $2004,88-94$.

[42]. D. G. Blazer, Self-efficacy and depression in late life: A primary prevention proposal. Aging \& Mental Health, 6, 2002, 315-324.

[43]. L. Peplua, and D. Perlman, Perspectives on loneliness. In L. Peplua \& D. Perlman (Eds), Loneliness: A sourcebook of current theory, research and therapy. (NY: John Wiley and Sons, 1982) 69-78.

[44]. S. Asher, and J. Paquentt, Loneliness and peer relations in childhood. Current Directions in Psychological Science, 12, (3), 2003, 75-78.

[45]. A. Rokach, From loneliness to belonging: A review. Psychology Journal, 8(2), 2011, $70-81$.

[46]. R. A. Davis, A cognitive - behavioural model of pathological internet use. Computer and Human Behaviour, 17, 2001, 187-195.

[47]. T. Lake, Loneliness (London: Sheldon Press, 1990).

[48]. L. Ryan, and M.L. Caltabiano, Development of a new resilience scale: The resilience in midlife scale (RIM Scale). Asian Social Science, 5(11), 2009, 39-51.

[49]. J. De Jong Gierveld, and F. Kamphuis, The development of a Rasch-Type Loneliness Scale. Applied Psychological Measurement, 9, 1985, 289-99.

[50]. J. De Jong Gierveld, and T. Van Tilburg, Manual of the Loneliness Scale (Amsterdam, the Netherlands: Vrije Universiteit, 1999).

[51]. M., Pinquart, and S. Sörensen, Influences on loneliness in older adults: A meta-analysis.” Basic and Applied Social Psychology, 23, 2001, 245-66.

[52]. A. Tsitsika, M. Janikian, E.C. Tzavela, T.M..,Schoenmakers, K. Ólafsson, E. Halapi, C. Tzavara, S. Wójcik, K. Makaruk, E. Critselis, K.W. Müller, M. Dreier, S. Holtz, K. Wölfling, A. Iordache, A., Oliaga, G. Chele, G., Macarie, and C. Richardson, Internet use and internet addictive behaviour among European adolescents: A cross-sectional study. Safer Internet plus programme, a multiannual Community Programme on promoting safer use of the Internet and new online technologies, 2013. http://ec.europa.eu/saferinternet

[53]. C.C. Frangos, C.C. Frangos, and S.I.Sotiropoulo, A meta-analysis of the reliability of Young's Internet Addiction Test. Proceedings of the World Congress on Engineering, London, U.K, 2012.

[54]. D. Akst, Procrastination, problematic internet addiction and resilience addiction no longer require a substance (The resilience Institute, 2011).

[55]. K. Chak, Shyness and locus of control as predictors of internet addiction and internet use, master thesis, school of journalism and communication, Chinese University of Hong Kong, 2003.

[56]. N.S. Ayaroglu, The relationship between internet use and loneliness of universitystudents. Yayimlanmamis yüksek lisans tezi, Orta Dogu Teknik Üniversitesi, Ankara, 2002.

[57]. E. Ceyhan, University students' problematic internet use in terms of reasons for internet use. 6th WSEAS International Conference on Education and Educational Technology, Italy, 2007.

[58]. J. Eldeleklioğlu, Gender, romantic relationships, Internet use, perceived social support and social skills as the predictors of loneliness. Eurasian Journal of Educational Research, 33, 2008, 127-140.

[59]. J. Kim, R. LaRose, and W. Peng, Loneliness as the cause and the effect of problematic Internet use: The relationship between Internet use and psychological well-being. Cyber Psychology \& Behaviour, 12(4), 2009, 451-455.

[60]. G. T. Kurtaran, Examining the variables predicted internet addiction, master thesis, Mersin University, Turkey, 2008.

[61]. J. Morahan-Martin, and P. Schumacher, Incidence and correlates of pathological internet use among college students. Computers in Human Behaviour, 16, 2000, 13-29.

[62]. M. Koc,. Internet addiction and psychopathology. The Turkish Online Journal of Educational Technology, 10 (1), $2011,143-148$. 